University of Nebraska - Lincoln

DigitalCommons@University of Nebraska - Lincoln

Publications from USDA-ARS / UNL Faculty

U.S. Department of Agriculture: Agricultural

Research Service, Lincoln, Nebraska

2006

Traps And Trapping Techniques For Adult Mosquito Control

Daniel L. Kline

USDA-ARS, Dan.Kline@ars.usda.gov

Follow this and additional works at: https://digitalcommons.unl.edu/usdaarsfacpub

Part of the Agricultural Science Commons

Kline, Daniel L., "Traps And Trapping Techniques For Adult Mosquito Control" (2006). Publications from USDA-ARS / UNL Faculty. 1042.

https://digitalcommons.unl.edu/usdaarsfacpub/1042

This Article is brought to you for free and open access by the U.S. Department of Agriculture: Agricultural Research Service, Lincoln, Nebraska at DigitalCommons@University of Nebraska - Lincoln. It has been accepted for inclusion in Publications from USDA-ARS / UNL Faculty by an authorized administrator of DigitalCommons@University of Nebraska - Lincoln. 
Journal of the American Mosquito Control Association, 22(3):490 496, 2006

Copyright $(2006$ by The American Mosquito Control Association, Inc.

\title{
TRAPS AND TRAPPING TECHNIQUES FOR ADULT MOSQUITO CONTROL
}

\author{
DANIEL L. KLINE \\ Center for Medical. Agricultural, and Veterinary Entomology, USDAlARS, 1600 SW 23rd Drive, \\ Gainesville, FL 32608
}

\begin{abstract}
An overview is presented of the recent advancements in research activities conducted to evaluate mosquito traps. insecticide-impregnated targets baited with combinations of attractants, and strategies for using mass trapping techniques for adult mosquito population management. Technologies that use semiochemicals (attractants), traps and targets, and mass trapping are relatively new for management of adult mosquito populations. To date. emphasis has been placed primarily on developing barriers of attractant-baited and insecticide-impregnated targets. The most successful continuous use of this type of technology has been at Stevens' Landing, Collier County, Florida. Recently, commercially available traps have been evaluated for their ability to reduce nuisance populations of mosquitoes. Whereas use of Mosquito Magnet ${ }^{\mathrm{TM}}$ Pro (MM-Pro) traps along a nature trail on an isolated island (Atsena Otie) in the Gulf of Mexico resulted in a significant reduction in annoyance caused by the black salt-marsh mosquito. Ochlerotatus taeniorhynchus (Wied.), a perimeter of the same traps did not result in the same level of mosquito reduction in a residential area in Gainesville, FL.
\end{abstract}

KEY WORDS Traps. mosquito control, attractunts, mass trapping, lure, kill

\section{INTRODUCTION}

Traditionally, control of adult mosquitoes in the United States has relied almost exclusively on the use of chemical insecticides. This strict reliance on chemical insecticides has resulted in increased public apprehension about exposure to these insecticides, environmental concerns, and increased reports of mosquito species developing resistance to a dwindling number of chemical insecticides approved for mosquito control. This reliance also has led to an increased interest over the past 2 decades in developing integrated pest management (IPM) programs that include better surveillance, source reduction, larvicides, and biological control as well as public education (Rose 2001). The IPM approach has worked well for control of the irmmature stages because there are many options to choose from, but few options exist for use against adult mosquitoes. Besides adulticides, available options consist of personal protection (contact repellents and protective clothing) and public education (e.g., stay indoors and avoid exposure to mosquitoes during peak biting activity times). The use of new emerging technologies needs to be encouraged to develop effective IPM programs targeting mosquitoes. One new technology that is under active investigation is the use of semiochemical-baited traps and targets for mass trapping or killing of adult mosquitoes.

Interest in exploring this technology for adult mosquito control was stimulated in 1989 when 25 scientists from the United States, Canada, the United Kingdom, and The Netherlands met in Minneapolis, MN, to participate in the First International Symposium on Hematophagous
Insect Attractants, sponsored by the Metropolitan Mosquito Control District. Optimism that attractant-based technology for adult mosquito control could be developed was based largely on the success that tsetse fly workers achieved with attractant-baited, insecticide-impregnated targets and traps in Zimbabwe and elsewhere in Africa (Takken et al. 1986; Vale et al. 1986, 1988; Willemse 1991; Vale 1993; Torr 1994). These baited targets replaced aerial drift-spraying of tsetse-infested bush with insecticides (endosulfan or deltamethrin) or by spraying the resting sites of tsetse (Alsopp 1984). Both techniques were expensive and logistically complex. Today, these techniques have been replaced completely in Zimbabwe by the use of attractant-baited, insecticide-impregnated targets and traps (Vale 1993).

The consensus of the international group was that attractant-baited targets and traps could play a significant role not only in mosquito surveillance but also in the control of adult mosquitoes. The extent of that role was the subject of considerable debate (Kline 1994). All agreed that although this technology has worked well for tsetse fly control, it remained to be proven that similar technology could be used successfully to control adult mosquitoes. Much of the success of the tsetse fly removal trapping programs was attributed to both the biological peculiarities of tsetse flies and the research programs that were funded to gain a better understanding of tsetse behavior, which resulted in the development of effective targets that combine visual and olfactory attractants used by tsetse flies to locate their hosts (Vale 1993, Jordan 1995). The vulnerability of 


,


tsetse flies to trapping-out systems stems from their unusual life cycle. Compared with other insects, tsetse flies have an extremely low intrinsic rate of population increase (Hargrove 1988). Thus. much of the skepticism that trapping-out can work against mosquitoes is based on the high intrinsic rate of population increase for most species.

This article reports on progress that has been made since the 1989 international symposium on developing and evaluating attractant-based technology and strategies for adult mosquito control. Traps have been important components in mosquito management programs (Rupp and Jobbins 1969); however, their role has been restricted to surveillance. Trapping data have been generally used to make decisions on the initiation or termination of control measures as well as to assess efficacy of control approaches. Therefore, at the time interest in investigating trapping-out technology for mosquito management began, only 2 basic types of traps were available: the New Jersey (NJ) light trap (Mulhern 1942) and the Centers for Disease Control (CDC) trap (Sudia and Chamberlain 1962). These traps were designed for routine surveillance and were not intended for mosquito control. Light and carbon dioxide $\left(\mathrm{CO}_{2}\right)$ (Rudolfs 1922; Reeves $1951,1953)$ were basically the only attractants available for use with these traps (reviewed in Service 1993). Thus, the consensus of the participants in the previously mentioned symposium and a series of symposia and workshops that followed on this emerging technology was that the greatest priority for this technology to succeed against mosquitoes was the development of more efficient and economical traps, targets. and attractants.

\section{INITIATION OF FIELD STUDIES ON AVAILABLE TRAPS AND DEVELOPMENT OF TARGETS}

The first field studies to evaluate the concept of adult mosquito control through the use of attractant-baited traps and targets were initiated in 1993. A collaborative research project was established between the USDA's Center for Medical, Agricultural, and Veterinary Entomology (CMAVE), Gainesville, FL, and the Collier Mosquito Control District (CMCD), Naples, FL, to evaluate the use of this technology against mosquito populations in a resort area located on the north end of Key Island. Key Island was an isolated island accessible only by boat. The predominant species on the island were Ochlerotatus taeniorhynchus (Wied.) $(84.7 \%)$, Culex nigripalpus Theobald (13.8\%), and Anopheles atropos Dyar and Knab (1.4\%) (Kline and Lemire 1998).

As indicated above, at the time this project was initiated only 2 basic types of traps were avail- able. Since the NJ trap requires household current, which was not available everywhere on Key Island, the battery-powered model 512 CDC-type trap was selected as the trap of choice. Attractants available were light, $\mathrm{CO}_{2}$, and 1 octen-3-ol (octenol), which had just been recognized as a mosquito attractant (Takken and Kline 1989). Light was not used because it would likely attract nontarget insects and would quickly drain the batteries. Thus, the $\mathrm{CDC}$ traps were baited only with $\mathrm{CO}_{2}$ and octenol. $\mathrm{CO}_{2}$ was metered from $9 \mathrm{~kg}$ compressed gas cylinders at $200 \mathrm{ml} /$ min by using a double-stage pressure regulator (Victor model VTS 453B; Victoria Equipment Company, Denton, TX) and delivered to its release point ca. $5 \mathrm{~cm}$ from the top trap entrance via polyethylene tubing. Octenol was released from microreaction vials ( $5 \mathrm{ml}$; Supelco, Bellefonte, PA) fitted with plastic lids and neoprene septa by using a wick (Dills $15-\mathrm{cm}$ pipe cleaner) system (Kline and Lemire 1998) that released ca. $4 \mathrm{mg} / \mathrm{h}$. This combination of attractants and release rates was based on studies conducted previously against these same mosquito species in the Florida Everglades (Tákken and Kline 1989; Kline et al. 1990, 1991a, 1991b). The traps were hung from metal poles so that the top of the trap was ca. $1.8 \mathrm{~m}$ above ground level.

A protective perimeter barrier was established between a resort area on the north end of Key Island and the suspected source of mosquitoes on the south end of the island. Fifty-two individual killing stations were established, spaced $16.5 \mathrm{~m}$ apart, forming a single line protective barrier around the designated resort area; each station was supplied with its own 9-kg tank of $\mathrm{CO}_{2}$. For the first year (1994), one $\mathrm{CO}_{2}(200 \mathrm{cc} / \mathrm{min})+$ octenol (ca. $4 \mathrm{mg} / \mathrm{h}$ )-baited CDC-type trap was used at each killing station.

In 1995, insecticide-impregnated targets were substituted for the traps (Kline and Lemire 1998). All other parameters remained the same. This approach is often referred to as "lure and kill." In this method, the attractant combination is basically used to lure the target insects to a device where they hopefully will be killed. Although still relying on insecticides, this approach has the advantages of greatly reducing the amount of insecticide applied, allowing the choice of when and where the treatments will be made, thereby greatly reducing the impact on nontarget organisms (Day and Sjogren 1994). The collapsible targets consisted of cylinders (ca. $60,25 \mathrm{~cm}$ in length $\times 53.21 \mathrm{~cm}$ in diameter) of $60 \%$ polypropylene black shade cloth (DeWitt Company, Sikeston, MO) treated with an emulsifiable concentrate formulation (120 gm/liter) of lambda-cyhalothrin at $0.2 \mathrm{~g}$ active ingredient $(\mathrm{AI}) / \mathrm{m}^{2}$. The upper surface of the cylinder also was covered with insecticide-impregnated shade cloth. The bottom was left open to allow mosquitoes to 
enter and rest on the inner surface of the target. Targets were suspended from the poles that had been used for the barrier traps in 1994, so the bottom was ca. $15 \mathrm{~cm}$ above ground level. The octenol vial and $\mathrm{CO}_{2}$ release tube were taped to a short stake located centrally under each target so odors were dispensed $\mathrm{ca} .67 \mathrm{~cm}$ above ground level. Each year, the effectiveness of the perimeter barrier was evaluated by means of similarly baited model $512 \mathrm{CDC}$-type traps placed on both sides of the barrier. Traps and targets performed equally well: however, there was no significant ( $P$ $>0.05$ ) reduction in mosquito abundance in the resort area when the barrier was functional.

CMCD continued this work in 1996. Instead of each target being supplied with $\mathrm{CO}_{2}$ from individual tanks at each target location, the tanks were connected through a manifold to a control panel, which maintained a constant flow to the targets. Octenol was released near the area of the target where the $\mathrm{CO}_{2}$ was released. The targets were sprayed with insecticide (either permethrin or lambda-cyalothrin) on a scheduled basis. CMCD has performed several studies with this design of attractant-baited barrier line, or modifications of it. Each study was conducted to test various target designs, target spacing, or other parameters to develop the most efficient system (Stivers 2005). Targets were placed along the pipeline and treated with insecticide every 2 wk. $\mathrm{CO}_{2}$ was released through the targets at a rate of $200 \mathrm{ml} / \mathrm{min}$. CDC surveillance traps were used to collect mosquitoes to determine the efficacy of the system. The data showed significant differences $(P<0.05)$ in the ratio of mosquitoes collected inside and outside of the line when the system was on compared with when it was off. However, the level of control that was achieved was considered to be insufficient for operational use (Stivers 2005).

In 1998, the CMCD began a study on the feasibility of using their attractant-baited barrier line technology at a condominium complex on Marco Island, FL, called Stevens' Landing. This site was surrounded by mangrove swamp that produced enormous broods of $O c$. taeniorhynchus. The goal of this study was to determine whether the barrier line could be effective in protecting a populated area from adult mosquitoes. The system design was very similar to the design used on Key Island, with ca. $2,400 \mathrm{ft}$ of pipeline around the entire community and CDC traps to determine the number and species of mosquitoes inside and outside the line (Stivers 2005). This study was conducted for 3 years, testing variables such as target spacing, target shape, rate of $\mathrm{CO}_{2}$ released, and octenol release method. The most efficient target spacing was $20 \mathrm{ft}$. The most effective target was "bucket" shaped, composed of regular weed block cloth hanging from the lid of a 5-gal bucket and hung from metal pipe. This target was either dipped in or sprayed with insecticide biweekly for control purposes. During the final year of the study, liquid octenol was replaced with commercial waxbased octenol lures (BioSensory, Willimantic, CT) (Stivers 2005). The 3 years of data showed that the line provided the residents with relief from mosquitoes. Statistical analysis demonstrated that there were fewer mosquitoes inside the barrier line when the system was on than when the system was off. The residents also noted the difference in mosquito abundance when the line was on or off. The system worked so well that the community at Stevens' Landing voted to have it installed permanently.

During winter 2001 , the $\mathrm{CMCD}$, in collaboration with Stevens' Landing, made the barrier line a permanent facility at the community. The system was upgraded by burying the pipelines, retrofitting the control panel with copper rather than plastic tubing, and replacing the 100-lb compressed $\mathrm{CO}_{2}$ tanks with cryogenic $\mathrm{CO}_{2}$ held in 500-lb tanks. The tanks were replaced weekly to provide the systern with enough gas to attract mosquitoes. CMCD purchased the materials for the pipeline and the targets and installed the entire system. The condominium association, however, was responsible for the costs of maintenance and operation. The permanent attractant-baited barrier line has been running at Stevens' Landing since summer 2001. CMCD no longer needs to aerially apply insecticide to the area, thereby reducing potential detrimental impact on nontarget organisms in the sensitive mangrove environment surrounding the community (Stivers 2005).

Although this control method has proven effective at Stevens' Landing, it is not a method that can be applied in all circumstances. Further testing is necessary to determine whether this approach can be equally effective in other areas.

\section{COMMERCIAL TRAPS}

In 1995, two private companies initiated programs to develop traps specifically designed for mosquito control, BioSensory, Inc. (Willamantic, CT) developed the Dragonfly that used $\mathrm{CO}_{2}$, octenol, and heat as attractants. The $\mathrm{CO}_{2}$ was released from compressed gas cylinders. Mosquitoes were killed by electrocution. Although this trap was made available to residential users, it was mainly developed for commercial applications and has never been marketed through retail outlets. In contrast, American Biophysics Corporation (North Kingston, RI) developed a series of traps known as Mosquito Magnets for both commercial and residential use (Kline 2002). These traps also used $\mathrm{CO}_{2}$, octenol, and heat as the main attractants. $\mathrm{CO}_{2}$ is 
generated by the combustion of propane. In some models, a thermoelectric generator was used to generate electricity to power the fans. This made the traps more portable and allowed them to be placed where most needed without reliance on either electrical mains or a portable generator.

After West Nile virus (WNV) invaded the United States in 1999, public concern for mosquito control increased. At this point, many companies decided to develop mosquito traps to sell to residential users. A plethora of traps have since been developed and marketed. These traps come in a huge variety of designs, attractant combinations, and capture technologies. Most of the commonly available traps use $\mathrm{CO}_{2}$ as the main attractant, which is generated either by the combustion of propane or supplied from cylinders of compressed gas. Many have been tested in a scientific manner to determine comparative ability to capture mosquitoes (Kline, unpublished data; Smith et al., http://pherec.org/decs-click on trapping systems); however, control efficacy has yet to be sufficiently established to warrant inclusion of these traps in any type of organized mosquito control activity.

\section{MASS TRAPPING BY USING COMMERCIAL TRAPS}

From August 2002 through October 2004 (Kline, unpublished data), a mass trapping experiment using the MM-Pro was conducted on a group of 3 small isolated islands, collectively known as Atsena Otie, located in the Gulf of Mexico ca. $1 \mathrm{mi}$ off the coast of Cedar Key, Florida. Atsena Otie is managed by personnel from the Lower Suwannee Wildlife Refuge (LSWR). The study was initiated at the request of the LSWR manager who wanted mosquitoes controlled on the islands but did not want pesticides to be used. Unfortunately, there was no historical baseline of mosquito trap collections for the island that could be used as a point of reference. However, ample anecdotal evidence was provided by the LSWR rangers and local residents, who consistently and frequently stated that from May through October the islands are unsuitable for human visitations. Shortly after the salt-marsh areas surrounding the islands are flooded, the islands become inundated with enormous populations of $O c$. taeniorhynchus. Visitation is difficult even when covered with repellent and protective clothing. This indeed was the situation that was encountered in August 2002 when the traps for this study were deployed. Individuals setting up the traps wore pants, long sleeve shirts and headnets, all of which were sprayed with Deep Woods OFF!rim (SC Johnson, Racine, WI). Any exposed skin also was treated with this repellent. As a measure of mosquito activity, one pant leg was pulled up to the knee. It took less than $15 \mathrm{~s}$ for the mosquitoes to cover all available exposed skin from knee to ankle.

The MM-Pro was selected as the "treatment" trap based on its superior performance in large cage trap efficacy studies conducted against laboratory reared Oc. taeniorhynchus. In these studies, the MM-Pro caught 1.6 times as many Oc. taeniorhynchus as its nearest competitor and resulted in the lowest landing and biting counts. Also, this trap is portable, because it uses a thermoelectric generator to produce electricity to operate its suction fans. This feature was important because no electricity was available on Atsena Otie. In addition to the $\mathrm{CO}_{2}$ and water vapor generated by the combustion of propane, each trap also was baited with octenol. This was a true test of the trap manufacturer's (American Biophysics, Inc., North Kingston, RI) claim that the MM-Pro will clear out a 1 -acre area in 2 weeks.

The island selected for the trap study was ca. 23 acres of land surrounded by salt marsh. A nature trail nearly bisected this island. Either 21 (2002 and 2003) or 22 (2004) MM-Pro traps were placed along this trail such that each trap covered a radius of ca. 1 acre. In 2002 and 2003, modified MM-Pro traps were used because the collection nets of the unmodified trap would fill up too quickly. Therefore, the traps were modified so that the mosquitoes were collected into an 11.5liter container instead of the standard net. By 2004 (16 months), population pressure on the island was reduced to a level that unmodified traps could be used.

Two MM-X traps, located $1 / 3$ and $2 / 3$ of the way along the trail were used as surveillance traps. These traps were baited with octenol and $500 \mathrm{ml} / \mathrm{min} \mathrm{CO}_{2}$ released from a $20-\mathrm{lb} \mathrm{com}-$ pressed gas tank. One similarly baited MM-X trap was placed on each of the 2 adjacent "untreated" islands. In 2002 and 2003, 2 additional MM-X traps were placed on the mainland in the LSWR for comparison. In 2004, $5 \mathrm{MM}-\mathrm{X}$ traps were scattered on the mainland throughout the city of Cedar Key. Each year the surveillance traps were operated for at least 2 wk before and after the treatment traps were turned on. In 2002 , the treatment traps were operated from August 23 through October 4; in 2003, from May 20 through October 14: and in 2004, from June 12 through October 19.

In 2002, biting pressure was significantly reduced within 2 wk of trap operation. In contrast to the pretreatment scenario of the exposed leg being completely covered with viciously biting mosquitoes from knee to ankle in $15 \mathrm{~s}$, no repellent was needed. From this point on, trap collections were made in shorts and short sleeve shirts. There were occasional blips of biting activity within a week after larval developmental sites were flooded either by rainfall events or by 
tides. Usually, these blips would last for only 1 or 2 days. Basically, this scenario was repeated each year after the traps had been operating for $2 \mathrm{wk}$. Each year the biting pressure progressively declined after each flooding event. This decline led to speculation that perhaps the "egg bank" was being depleted due to the enormous number of potential first-time egg layers being removed from the island's population. Mosquito immigration and ernigration were unknown factors. The data are still being analyzed, but preliminary analyses indicate that by the end of the 3rd yr there was excellent (80-90\% population reduction), sustained control despite the area being hit by multiple hurricanes.

Additional mass trapping studies were conducted in residential areas of Gainesville, FL, during the 2003 and 2004 mosquito seasons in a collaborative study between the USDA, CMAVE research laboratory, and the Gainesville Mosquito Abatement program, Gainesville, FL (Kline, unpublished data). These studies were conducted to evaluate the efficacy of this technology in a nonisolated area, where mosquito diversity was high ( $>33$ species) and the areas to be protected were surrounded by numerous larval developmental sites. Two separate neighborhoods were surrounded by 12 unmodified MM-Pro traps. Each trap used octenol as an additional attractant. CDC traps and landing rate counts were used twice per week to monitor mosquito species composition and abundance within the perimeters of these "treated areas" compared with similar "untreated" (not surrounded by MM-Pro traps) residential areas. Preliminary analysis indicates moderate control, ca. 50\% reduction in captures by the $\mathrm{CDC}$ monitoring traps in "treated" compared with "untreated" residential neighborhoods. Similar unpublished studies using MM-Pro traps in residential areas have been conducted in St. Augustine, FL (Xue, personal communication). Residents in "treated" areas in both Gainesville and St. Augustine perceived the traps to be effective at reducing mosquito abundance in their yards.

In another residential trapping study, the Salt Lake City Mosquito Abatement District used the MM-Pro in an attempt to give residents some relief from $O_{c}$. sierrensis, a tree hole mosquito species (1lougaard and Dickson 1999). These mosquitoes are very aggressive, which makes them a neighborhood nuisance. Because this species remains close to its source area, removal trapping is considered a viable control method. The MM-Pro traps were used at several locations over summer 1999. When surveyed by telephone, homeowners responded that the MM-Pro traps had really helped and that the mosquitoes were under control. Abatement personnel concluded that the MM-Pro was an effective tool in helping to control this tree hole mosquito species. They stated that it by no means eliminated all of the mosquitoes, but it did give people some relief and peace of mind and the assurance that the abatement district was trying to help reduce the mosquito nuisance.

\section{SUMMARY AND CONCLUSIONS}

Trapping-out using semiochemical-baited targets/traps for mosquito population management is a relatively new technology. The tsetse mass trapping effort illustrates that the technology can be successful against a hematophagous pest. Despite the tsetse fly success story, however, many, if not most, medical entomologists, mosquito scientists. and control personnel are skeptical that trapping-out can be used effectively against adult mosquitoes.

The tsetse fly story illustrates that much basic research into the target species' biology, behavior, and ecology is a prerequisite for success. It also demonstrates that a multidisciplinary effort is required. The few mosquito studies that have been conducted and presented in this article indicate that this technology has promise for mosquito population management, but the challenges to success seem greater than for controlling tsetse flies. Mosquitoes are more prolific than tsetse and most travel greater distances. There is also a greater diversity of nuisance species in any given geographic area with mosquitoes than occurs with tsetse flies.

The mosquito studies presented in this article illustrate some of the promises and some of the problems encountered so far. Both the attractantbaited targets and MM-Pro studies indicated promise for managing populations such as $O c$. taeniorhynchus, which is very attracted to the combination of attractants used $\left(\mathrm{CO}_{2}\right.$, octenol, heat, and water vapor) in these studies. The more attractants used (e.g., MM-Pro traps used all types of attractants compared with targets that did not use heat and water vapor), the better the population reduction. The technology worked best on the isolated islands where one species $(O C$. taeniorhynchus) was clearly the dominant species compared with mainland residential areas such as Gainesville where many important nuisance species of different genera were present. Thus, the Gainesville study demonstrates that "one size does not fit all." Different attractant combinations, delivery systems, and trap types may be required to attract and effectively capture different populations.

Another scenario in which the technology looks promising is in areas like Salt Lake City, UT, where a single dominant nuisance species (Oc. sierrensis), remains in backyards close to the larval developmental sites (tree holes).

So far, studies using mass trapping technology against adult mosquitoes have been conducted on 
a limited spatial and temporal scale. They have not progressed beyond small-scale trials. Before large-scale mosquito trials are conducted it is essential that we acquire a better understanding of the spatial distribution of target species, their dispersal patterns, and their population dynamics in general. Studies with simulation models of tsetse (Hargrove 1988) and mosquitoes (Ritchie and Montague 1995) have shown that population dynamics is most sensitive to dispersal and adult mortality parameters. The dispersal capacity of targeted mosquito species can have a great influence on the potential of attractant-baited trapping systems. A high dispersal rate, as is present in Oc: taeniorhynchus (Provost 1957), could impose problems in attempts to reduce local populations, because the risk of reinvasion would be high. In the small-scale tests with $O c$. taeniorhynchus on both Key Island and Atsena Otie, whenever a flooding event occurred in the larval developmental sites, several days later the perimeter of targets or array of MM-Pro traps would be overwhelmed (but only temporarily). The technique might have greater potential against mosquitoes with a relatively small dispersal activity, such as Cx. nigripalpus (Nayar et al. 1980) or $O_{c}$. sierrensis (Hougaard and Dickson 1999).

Knowledge of the spatial distribution of targeted species is also necessary as it relates to finding an optimal placement strategy for traps or targets for maximum impact on targeted species (Kline 1998). Questions that need to be answered include the impact of location, spacing, and height of deployed traps or targets on the effectiveness of the system. Day and Sjogren (1994) describe 4 approaches to the deployment of traps or targets: 1) to attract mosquitoes away from where protection is desired, 2) to situate traps around the protection area as a perimeter barrier, 3) to place traps or targets individually within the protection area, and 4) to intercept mosquitoes during dispersal from breeding sites or resting sites.

Knowledge of basic population parameters and dynamics is also essential to determine the extent of trapping required to attain a certain level of population control. Weidhaas and Haile (1978) estimated that, depending on the bistic potential of the mosquito species, the trapping requirement could be as high as $40 \%$ per day to achieve a substantial reduction in the population. Service (1995) theorized that the immense biotic potential and population densities of mosquitoes make it unlikely that traps or targets alone could reduce mosquito populations to an acceptable level. This scenario is often encountered for certain floodwater mosquitoes, such as $O c$. takniorhynchus and Ae vexans, which are characterized by rapid and large explosive population outbreaks. Yet the studies cited above reveal that in selected circumstances control can be achieved with such species by attractant-baited traps or targets. Perhaps attractant-baited traps could be used equally or more effectively in areas where mosquito densities remain relatively low or for species that breed in permanent water bodies and are often characterized by a more gradual population buildup.

Acceptance by the public and professional mosquito control community of new technologies, such as mass trapping and other biological control technologies, will not be easy because they have grown accustomed to the immediate control obtained through spraying with chemical insecticides, despite recognizing the negative side effects. Nevertheless, the use of semiochemicalbaited traps or targets, either locally or on an areawide scale, needs to be perfected to the level that it can be incorporated into selected integrated mosquito management programs. Parks, resorts, golf courses, and other recreation areas may be good candidates for use of this technology. It is important to educate residents, decisionmakers, and the general public about both the potential and the constraints of attracting and trapping, even though a lower level of control may need to be accepted in certain circumstances. With the development of sufficiently effective traps and increased diversity of effective attratctant combinations for different mosquito species, trapping systems could be used routinely in the future as behavioral control measures and be added to the growing list of biologically based technologies for mosquito control.

\section{REFERENCES CITED}

Allsopp R. 1984. Control of tsetse flies (Diptera: Glossinidae) using insecticides: a review and future prospects. Bull Entomol Res $74: 1 \ldots 23$.

Day JF, Sjogren RD. 1994. Vector control by removal trapping. Am I Trop Med Hyg 50:126 133.

Hargrove JW. 1988. Tsetse: the limits to population growth. Med Vet Entomol 2:203-217.

Hougaard B, Dickson SL. 1999. The Mosquito Magnet a new tool in controlling tree hole mosquitoes. In: Proveedings of 52nd amnual meeting of the Utah Mosquito Abatement Assoxiation p 4-8.

Jordan AM. 1995. Control of tsetse flies (Diptera: (ilossinidae) with the aid of attractants. I Am Mosq Control Assoc $11: 249-255$.

Kline DL. 1994. Introduction to symposium on attractants for mosquito surveillance and control. $J$ Am Mosq Control Assoc 10:252-257.

Kline DL. 1998. The future of attractant-baited traps/ targets in mosquito control. In: Florida mosquito control: conference on urban growith and its impact on future mosquito control problems and opportunities. Florida Coordinating Council on Mosquito Control. Gainesville. FL: University of Florida. p 33 35.

Kline DL. 2002. Evaluation of various models of propane-powered mosquito traps. J Vector Ecol 27:1 7 
Kline DL, Lemire GF. 1998. Evaluation of attractant baited traps/targets for mosquito management on Key Island, Florida, USA. J Vector Ecol 23:171-185.

Kline DL, Bernier UR, Posey KP. Barnard DR. 2003. Olfactometric evaluation of spatial repellents for Aedes aegypti. J Med Entomol 40:463-467.

Kline DL, Dame DA, Meisch MV, 1991a. Evaluation of 1-octen-3-ol and carbon dioxide as attractants for mosquitoes associated with irrigated rice fields in Arkansas. J Am Mosq Control Assoc 7:165-169.

Kline DL, Takken W, Wood JR, Carlson DA. 1990. Field studies on the potential of butanone, carbon dioxide, honey extract, 1-octen-3-ol, L-lactic acid and phenols as attractants for mosquitoes. Med Vet Entomol 4:383-391.

Kline DL, Wood JR, Cornell JA. 1991b. Interactive effects of 1-octen-3-ol and carbon dioxide on mosquito (Diptera; Culicidae) surveillance and control. J Med Entomal 28:254-258.

Mulhern T. 1942. New Jersey mechanical trap for mosquito surveys. NJ Agric. Exp. Stn. Circ. 421.8 Reprinted 1985. J Am Mosq Control Assoc 1:411-418.

Nayar JK. Provost MW, Hansen CW. 1980. Quantitative bionomics of Culex nigripalpus (Diptera: Culicidae) populations in Florida. 2. Distribution, dispersal and survival patterns. J Med Entomol 17:40 -50.

Provost MW. 1957. The dispersal of Aedes taenior hynchus. 2. The second experiment. Mosq News 17: 233-247.

Reeves WC. 1951. Field studies on carbon dioxide as a possible host stimulant to mosquitoes. Proc Soc Exp Biol Med 77:64-66.

Reeves WC. 1953. Quantitative field studies on a carbon dioxide chemotropism of mosquitoes. Am $J$ Trop Med Hyg 2:325-331.

Ritchie SA, Montague CL. 1995. Simulated populations of the black salt marsh mosquito (Aedes taeniorhynchus) in a Florida mangrove forest. Ecol Model 77:123-141.

Rose RI. 2001. Pesticides and public health: integrated methods of mosquito management. Emerg Infect Dis $7: 17-23$.

Rudolfs W. 1922. Chemotropism of mosquitoes. Bull. N.I Agric, Exp. Sin., No. 367. 23 p.

Rupp HR, Jobbins DM. 1969. Equipment for mosquito surveys: two recent developments. In: Proceedings of the 56th Annual Meeting of the New Jersey Mosquito
Extermination Association. 1969 March 19-21; At. lantic City, NJ. p 183-188.

Service MW. 1993. Mosquito ecology; field sampling methods. 2nd ed. Elsevier Applied Science, New York.

Service MW. 1995. Can we control mosquitoes without pesticides? A summary. I Am Mosq Control Assoc 11:290-293.

Sudia WD. Chamberlain RW. 1962. Battery-operated light trap, an improved model. Mosq News 22: $126-129$

Stivers J. 2005. Research progranns. Stevens" Landing, Naples, FL. http:/www.colliermosquito.org/ print-Stevens

Takken W, Kline DL. 1989. Carbon dioxide and 1octen-3mol as mosquito attractants. $J$ Am Mosq Control Assoc 5:311-316.

Takken W, Oladunmade MA, Dengwat L, Feldman HU. Onah JA, Tenabe SO, Hamann HJ, 1986. The eradication of Glossina palpalis palpalis (RobineauDesvidy) (Diptera: Glossinidae) using traps, insecticide-impregnated targets and the sterile insect technique in central Nigeria. Bull Entomol Res 76: $275-286$.

Torr SJ. 1994. The tsetse (Diptera: Glossinidae) story: implications for mosquitoes. $J$ Am Mosq Control Assoc 10:258-265.

Vale GA. 1993. Development of baits for tsetse flies (Diptera: Glossinidae) in Zimbabwe. $J$ Med Entomol 30:831-842

Vale GA, Hargrove JW, Cockbill GF, Phelps RJ. 1986. Field trials of baits to control populations of Glossina morsitans morsitans Westwood and $G$, pallidipes Austen (Diptera: Glossinidae). Bull Entomol Res 76:179-193.

Vale GA, Lovemore DF, Flint S, Cockbill GF. 1988. Odour-baited targets to control tsetse flies, Glossina spp. (Diptera: Clossinidae) in Zimbabwe. Bull Entomol Res 78:31-49.

Weidhaas DE, Haile DG. 1978. A theoretical model to determine the degree of trapping required for insect population control. Bull Entomol Soc Am 24:18-20.

Willernse L. 1991. A trial of odour baited targets to control the tsetse fly, Glassina morsitans centralis (Diptera: Glossinidae) in west Zambia. Bull Entomol Res 81:351-357. 